\title{
Cantharidin is conserved across phylogeographic lineages and present in both morphs of Iberian Berberomeloe blister beetles (Coleoptera, Meloidae)
}

\author{
CAROLINA BRAVO ${ }^{1 *}$, PALOMA MAS-PEINADO², LUIS MIGUEL BAUTISTA ${ }^{1}$, \\ GUILLERMO BLANCO ${ }^{1}$, JUAN CARLOS ALONSO ${ }^{1}$ and MARIO GARCÍA-PARÍS ${ }^{2}$ \\ ${ }^{1}$ Department of Evolutionary Ecology, Museo Nacional de Ciencias Naturales-CSIC, José Gutiérrez \\ Abascal 2, 28006 Madrid, Spain \\ ${ }^{2}$ Department of Biodiversity and Evolutionary Biology, Museo Nacional de Ciencias Naturales-CSIC, \\ José Gutiérrez Abascal 2, 28006 Madrid, Spain
}

Received 28 January 2016; revised 28 September 2016; accepted for publication 25 October 2016

\begin{abstract}
Intra-specific coloration polymorphism coupled with an ancient process of lineage differentiation in Berberomeloe majalis (Linnaeus, 1758) offers the opportunity to analyse the temporal scenario in which the correlation between toxicity and coloration might have evolved. Based on phylogenetic and phylogeographic analyses, we identified the timing for the split between red-striped and entirely black morphotypes of B. majalis. To evaluate whether coloration patterns and toxicity are related in this species, we quantified the concentration of cantharidin across morphotypes and phylogeographic lineages. Phylogenetic analyses based on cox1 mitochondrial DNA sequences recovered three major clades where both morphotypes were intermingled, indicating a multiple homoplastic origin for the entirely black coloration. Our analyses showed that cantharidin content did not differ between morphs of B. majalis; however, it significantly increased in haemolymph in females kept isolated from males, which reveals the females' ability either to concentrate cantharidin towards haemolymph or to synthesize cantharidin themselves. Lack of monophyly and absence of genetic isolation in both morphotypes favour the hypothesis of a recent homoplastic phenomenon to explain the loss of the striped pattern. Our phylogenetic and phylogeographic analyses show that changes in coloration are recent, suggesting that the ancient pressures that fixed and maintained red-striped colorations are no longer acting today on $B$. majalis. The absence of change in cantharidin content (i.e. entirely black and red-striped specimens are equally poisonous) suggests that the evolution of colour polymorphisms in B. majalis is probably decoupled from toxicity.
\end{abstract}

ADDITIONAL KEYWORDS: meloids - phylogeny - polymorphism - toxicity.

\section{INTRODUCTION}

Predation by visual hunters is considered one of the most important selection pressures involved in the evolution of colour patterns of animals (Gamberale-Stille \& Tullberg, 1999; Summers \& Clough, 2001; Lindstedt et al., 2011). Conspicuous warning colorations are frequently associated with unpalatability or toxicity (Lindstedt et al., 2011), and consequently detectability, memorability, and ease of identification are advantageous cues upon which selection may act (Roper, 1990; Aronsson \& Gamberale-Stille, 2008). Although predation might favour intermediate signals (i.e. allowing

*Corresponding author. E-mail: carolina.bravo.parraga@gmail.com for signal variation, see Rowe, Lindstrom \& Lyytinen, 2004; Darst, Cummings \& Cannatella, 2006), toxicity and coloration patterns remain invariant as long as predation pressure is active. However, predation risk may vary significantly through time, likely changing the benefits of warning patterns (Mappes, Marples $\&$ Endler, 2005). If selective pressures are reduced or eliminated by a change in the predator community, the system would be free to change, either retaining the toxicity and conspicuous coloration, returning to the ancestral coloration and even losing toxicity, or allowing for colour polymorphisms with toxic and/or nontoxic specimens (Blomberg \& Garland, 2002).

Colour polymorphisms in toxic or unpalatable species can also be maintained by alternating selective 
pressures such as changes in substrate which might modify visibility (Endler, 1978; Blanco \& Bertellotti, 2002; Bond \& Kamil, 2006), or by sexual selection (Eisner \& Meinwald, 1995; Ayasse, Paxton \& Tengö, 2001). Colour polymorphisms might then be associated with varying degrees of toxicity or unpalatability as a consequence of tandem evolution (Summers \& Clough, 2001; Cooper, 2008) or concurrent reciprocal selection (Weldon, 2013; Weldon \& Burghardt, 2015). Therefore, the consequences of relaxing selective pressures on warning coloration indicating toxicity would be related to the temporal scenario in which warning colorations were free to change (Harvey et al., 1982; Gamberale-Stille \& Guilford, 2004; Skelhorn \& Rowe, 2010). Empirical evidence in support of this reasonable theoretical framework is scarce. The analyses of alternative temporal frameworks within a phylogenetic context to detect changes in selection pressures on warning coloration could offer new insights into this issue (Brower, 1996; Summers \& Clough, 2001; Beltrán et al., 2002; Mappes et al., 2005). Here, we study colour polymorphisms in toxic blister beetles (Coleoptera: Meloidae) to contribute to such new insights.

Blister beetles of the family Meloidae are capable of synthesizing cantharidin, which is a monoterpene anhydride compound highly toxic to vertebrates and invertebrates (Eisner et al., 1990; Dettner, 1997; Barr et al., 1998). A first obvious function of cantharidin could be to deter predators. The efficiency of cantharidin as a deterrent for predators (Carrel \& Eisner, 1974) and its poisoning effects on livestock have been widely reported (Bahme, 1968; Ray et al., 1980; Beasley et al., 1983). In fact, only a few species consume blister beetles (Eisner et al., 1990; Bartram \& Boland, 2001; Bravo et al., 2014, 2016). A second function of cantharidin could also be to help blister beetles avoid internal parasites, due to its fungicidal, nematocidal, and bactericidal properties (Carrel \& Eisner, 1974; Bravo et al., 2014). Among blister beetles, males usually have more cantharidin than females (Capinera, Gardner \& Stermitz, 1985; Blodgett, Carrel \& Higgins, 1991; Carrel et al., 1993; Carrel, 1999; Nikbakhtzadeh \& Tirgari, 2002; Mebs et al., 2009; Nikbakhtzadeh et al., 2012), and apparently only males are able to synthesize this toxin (Sierra, Woggon \& Schmid, 1976; Holz et al., 1994). Therefore, cantharidin content could also be under sexual selection pressures. Female blister beetles would acquire it from males during copulation. Nevertheless, there are some research reports where no final conclusions about the biosynthesis pathway of cantharidin are provided (Yin \& Jin, 2010). Thus, new studies focused on sexual differences of cantharidin biosynthesis in blister beetles are necessary. In this study, we test sexual differences in synthesis of cantharidin in blister beetles. Using a multidisciplinary approach, we also infer the historic process which gave rise to colour polymorphism in a species of blister beetle, and analyse the relationship between coloration pattern and toxicity.

Although a correlation between conspicuous coloration and its function as a warning signal to predators has not been tested in Meloidae, many species of blister beetles display bright and conspicuous colorations and occasionally may adopt a frightening attitude (Varley, 1939; Pinto, 1975). One extreme case is represented by giant beetles of the genus Berberomeloe Linnaeus in the Iberian Peninsula. The coloration in the widespread species Berberomeloe majalis (Linnaeus, 1758) is characterized by the presence of bright blood-red or orange transverse stripes across a solid black swollen abdomen (the length of this beetle may reach up to $9 \mathrm{~cm}$, Fig. 1A, García-París, 1998). A similar conspicuous coloration, including transverse

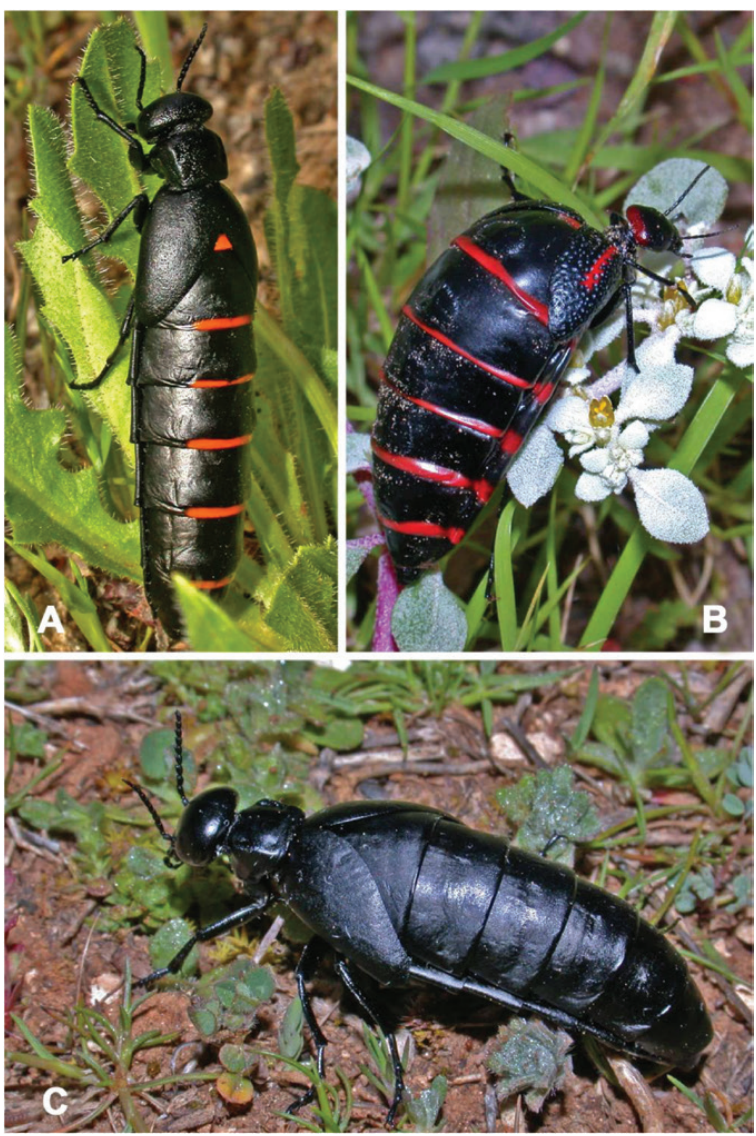

Figure 1. (A) Red-striped morph of Berberomeloe majalis, characterized by the presence of bright blood-red or orange transversal stripes across a solid black swollen abdomen; (B) genus Megetra, whose coloration has evolved independently of genus Berberomeloe; and (C) black morphotype of B. majalis, characterized by the entirely black body without any red stripes. 
red stripes on a swollen abdomen, has evolved independently in the distantly related North American genus Megetra LeConte (Fig. 1B), suggesting that this coloration pattern is subjected to high selective pressure. The three species of the genus Megetra show the characteristic striped coloration (Fig. 1B) with no intra-specific variability for this trait (Selander, 1965; Pinto, 1984). However, B. majalis varies extensively in colour. Populations of entirely black specimens without any red markings (Fig. 1C) are found scattered over much of the distribution range of $B$. majalis. These populations are often found close to populations consisting of red-striped specimens, but both morphs seem to be spatially segregated and no mixed series have been found in the field (García-París, 1998; personal observation).

A recent hypothesis on the geographic distribution of genetic variability of $B$. majalis in the Iberian Peninsula (Percino-Daniel, Buckley \& García-París, 2013) revealed the existence of differentiated mitochondrial lineages within the species. The presence of intra-specific coloration polymorphism coupled with an ancient process of lineage differentiation in B. majalis offers an excellent opportunity to analyse the correlation between toxicity and conspicuousness and the temporal scenario in which the relation might have evolved.

We use two approaches to study this issue. First, we evaluate the temporal frame in which conspicuous coloration is lost, by phylogenetic and phylogeographic analyses of Iberian populations of B. majalis, with emphasis in (1) identifying the relationship between red-striped and entirely black populations and (2) determining the timing for the split between the morphotypes. Second, we quantify the concentration of cantharidin across sexes, morphotypes, and phylogeographic lineages, with the specific objective of (3) evaluating whether toxicity and conspicuous coloration are related in the genetically diverse $B$. majalis .

\section{METHODS}

\section{SAMPLING}

Sampling of B. majalis for phylogeographic and phylogenetic analyses was designed to cover a large portion of the species' known distribution range in the Iberian Peninsula $(n=77)$ and Morocco $(n=5$; Table 1 ; Fig. 2A), in order to capture the mitochondrial diversity of the species in the area. Sampling included specimens of red-striped and entirely black populations (Fig. 2A). Specimens for cantharidin analyses were collected in April-May 2012 in Central Spain, and also included both coloration patterns ( 29 red-striped and 57 entirely black) (Fig. 2B).

\section{MiTOCHONDRIAL DNA ANALYSES}

Tissue was extracted from the coxae or femora of 63 specimens preserved in ethanol ( $96^{\circ}$ to absolute) stored at $-20^{\circ} \mathrm{C}$. Total genomic DNA was extracted using protocols described by Alcobendas et al. (2008). Polymerase chain reaction (PCR) was used to amplify 657 base pairs (bp) of the mitochondrial Cytochrome Oxidase I gene (cox1), using the primers LCO1490 (Folmer et al., 1994) and COI-H (Machordom et al., 2003). PCR reactions were performed as explained in Percino-Daniel et al. (2013). Sequencing was as indicated in Martínez-Solano et al. (2006).

Sequences were compiled using Sequencer v.4.9 to assemble and to edit the sequence contigs. The cox 1 sequences were aligned in Mesquite v.3.04 (Maddison $\&$ Maddison, 2015) to correct the final alignments. The data set consisted of 67 specimens from $B$. majalis and 15 additional specimens obtained by Percino-Daniel et al. (2013) (GenBank accession numbers: KC853086KC853103). For the phylogenetic analyses, we included the other known species of the genus, Berberomeloe insignis (Charpentier, 1818), as a related outgroup.

\section{CANTHARIDIN CONTENT ANALYSES}

We analyzed cantharidin content in haemolymph and in the dried body. Individuals were subjected to two extractions of haemolymph to test whether cantharidin content increased or decreased in the second extraction compared to the first. In this way we aimed to explore differences between sexes in the capability of cantharidin synthesis. We also measured the cantharidin content in the dry body to analyse the relationship between cantharidin content and phylogeny.

To analyse the sexual differences in cantharidin synthesis, cantharidin content was examined in haemolymph ( $n=96$ haemolymphs of 72 individuals, Table S1). Defensive behaviour of B. majalis consists of thanatosis and evident autohaemorrhea (Bologna, 1989, 1991), which may take place even without direct contact with the suspected aggressor. Seventy-two specimens of $B$. majalis were kept indoors in plastic boxes $(15 \times 10 \times 5 \mathrm{~cm}, \mathrm{~W} \times \mathrm{L} \times \mathrm{H}$, one adult per box $)$. Cages were cleaned and fresh leaves of Vicia sativa and flowers of Asteraceae were provided on a daily basis. Beetles were sexed by observing their external sexually dimorphic characters (last visible abdominal segment). Individuals were weighed every other day to control for any dehydration, and beetles which lost more than $10 \%$ of their weight were discarded from all analyses $(n=9)$. We took advantage of the $B$. majalis bleeding reflex to obtain $0.0001-0.4 \mathrm{~mL}$ of haemolymph. Haemolymph droplets expelled through body segment joints, either along legs or around neck, were collected in $2 \mathrm{~mL}$ tubes while gently handling specimens using 
Table 1. Localities, number and species information, and GenBank accession numbers for the sequences and specimens used in the molecular study.

\begin{tabular}{|c|c|c|c|}
\hline Taxon & Locality (country: province: town) & Voucher field number & GenBank accession number \\
\hline B. majalis & Spain: Albacete: El Bonillo & MAB140 & KC853090 \\
\hline B. majalis & Spain: Albacete: El Bonillo & MAB169 & KC853089 \\
\hline B. majalis & Spain: Almería: El Puntal, Uleila & MAB185 & KC853091 \\
\hline B. majalis & Spain: Almería: El Puntal, Uleila & MAB197 & KC853092 \\
\hline B. majalis & Spain: Burgos: Monasterio de Rodilla & MAB116 & KC853094 \\
\hline B. majalis & Spain: Burgos: Monasterio de Rodilla & MAB123 & KC853093 \\
\hline B. majalis & Spain: Cáceres: 3 km S Navas del Madroño & MAB174 & KC853095 \\
\hline B. majalis & Spain: Cáceres: 3 km S Navas del Madroño & MAB175 & KC853096 \\
\hline B. majalis & Spain: Cádiz: 3 km S Alcalá de los Gazules & MAB107 & KC853097 \\
\hline B. majalis & Spain: Ciudad Real: 2 km N Carrión de Calatrava & MAB103 & KX495702 \\
\hline B. majalis & Spain: Ciudad Real: 2 km N Carrión de Calatrava & MAB105 & KX495703 \\
\hline B. majalis & Spain: Ciudad Real: 6 km S Malagón & MAB156 & KX495729 \\
\hline B. majalis & Spain: Ciudad Real: Argamasilla de Calatrava & MAB138 & KX495719 \\
\hline B. majalis & Spain: Ciudad Real: Piedrabuena & MAB500 & KC853098 \\
\hline B. majalis & Spain: Ciudad Real: Piedrabuena & MAB501 & KC853099 \\
\hline B. majalis & Spain: Cuenca: Fuentes & MAB110 & KX495706 \\
\hline B. majalis & Spain: Cuenca: Villar de Cañas & MAB163 & KX495732 \\
\hline B. majalis & Spain: Cuenca: Villarejo de Fuentes & MAB139 & KX495720 \\
\hline B. majalis & Spain: Granada: Santa Cruz del Comercio & MAB115 & KX495708 \\
\hline B. majalis & Spain: Guadalajara: $5 \mathrm{~km}$ ENE Illana & MAB168 & KX495735 \\
\hline B. majalis & Spain: Guadalajara: 5 km NE Illana & MAB126 & KX495712 \\
\hline B. majalis & Spain: Guadalajara: 5 km O Cogolludo & MAB142 & KX495721 \\
\hline B. majalis & Spain: Guadalajara: 5 km O Cogolludo & MAB147 & KX495724 \\
\hline B. majalis & Spain: Guadalajara: Uceda & MAB109 & KX495705 \\
\hline B. majalis & Spain: Guadalajara: Uceda & MAB118 & KX495709 \\
\hline B. majalis & Spain: Guadalajara: Uceda & MAB134 & KX495717 \\
\hline B. majalis & Spain: Guadalajara: Uceda & MAB135 & KX495718 \\
\hline B. majalis & Spain: Guadalajara: Uceda & MAB150 & KX495726 \\
\hline B. majalis & Spain: Guadalajara: Uceda & MAB167 & KX495734 \\
\hline B. majalis & Morocco: Oumallal: Oum er Rbia (Middle Atlas) & MAB176 & KX495739 \\
\hline B. majalis & Morocco: Oumallal: Oum er Rbia (Middle Atlas) & MAB177 & KX495740 \\
\hline B. majalis & Morocco: Oumallal: Oum er Rbia (Middle Atlas) & MAB178 & KX495741 \\
\hline B. majalis & Morocco: Oumallal: Oum er Rbia (Middle Atlas) & MAB179 & KX495742 \\
\hline B. majalis & Morocco: Oumallal: Oum er Rbia (Middle Atlas) & MAB180 & KX495743 \\
\hline B. majalis & Spain: Jaen: 10 km N Ubeda & MAB161 & KX495731 \\
\hline B. majalis & Spain: Jaén: 10 km N Ubeda & MAB119 & KX495710 \\
\hline B. majalis & Spain: Jaén: 10 km N Ubeda & MAB127 & KX495713 \\
\hline B. majalis & Spain: Jaén: Orcera & MAB153 & KX495727 \\
\hline B. majalis & Spain: Madrid: 1 km NE Meco & MAB203 & KX495753 \\
\hline B. majalis & Spain: Madrid: $1 \mathrm{~km}$ SE Villanueva de la Torre & MAB202 & KX495752 \\
\hline B. majalis & Spain: Madrid: 3 km E Villaconejos & MAB157 & KX495730 \\
\hline B. majalis & Spain: Madrid: 4 km S Colmenar de Oreja & MAB146 & KC853100 \\
\hline B. majalis & Spain: Madrid: 4 km S Colmenar de Oreja & MAB159 & KC853101 \\
\hline B. majalis & Spain: Madrid: 5 km NE Molino de la Aldehuela & MAB133 & KX495716 \\
\hline B. majalis & Spain: Madrid: 5 km NE Molino de la Aldehuela & MAB172 & KX495738 \\
\hline B. majalis & Spain: Madrid: 5 km S Villaconejos & MAB164 & KX495733 \\
\hline B. majalis & Spain: Madrid: Alcalá de Henares & MAB186 & KX495745 \\
\hline B. majalis & Spain: Madrid: Alcalá de Henares & MAB198 & KX495751 \\
\hline B. majalis & Spain: Madrid: Brea de Tajo & MAB191 & KX495750 \\
\hline B. majalis & Spain: Madrid: Canencia & MAB187 & KX495746 \\
\hline B. majalis & Spain: Madrid: Colmenar de Oreja $\star$ & Ber85 & KX495697 \\
\hline
\end{tabular}


Table 1. Continued

\begin{tabular}{|c|c|c|c|}
\hline Taxon & Locality (country: province: town) & Voucher field number & GenBank accession number \\
\hline B. majalis & Spain: Madrid: Colmenar de Oreja $\star$ & Ber90 & KX495698 \\
\hline B. majalis & Spain: Madrid: Colmenar de Oreja $\star$ & Ber91 & KX495699 \\
\hline B. majalis & Spain: Madrid: Colmenar de Oreja $\star$ & Ber92 & KX495700 \\
\hline B. majalis & 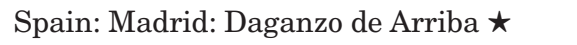 & Ber136 & KX495696 \\
\hline B. majalis & Spain: Madrid: Daganzo de Arriba $\star$ & Ber113 & KX495689 \\
\hline B. majalis & Spain: Madrid: Montejo de la Sierra & MAB183 & KX495744 \\
\hline B. majalis & Spain: Madrid: Montejo de la Sierra & MAB189 & KX495748 \\
\hline B. majalis & Spain: Madrid: Montejo de la Sierra & MAB190 & KX495749 \\
\hline B. majalis & Spain: Madrid: Rivas de Jarama & MAB100 & KX495701 \\
\hline B. majalis & Spain: Madrid: Talamanca $\star$ & Ber131 & KX495693 \\
\hline B. majalis & Spain: Madrid: Talamanca $\star$ & Ber133 & KX495694 \\
\hline B. majalis & Spain: Madrid: Talamanca $\star$ & Ber135 & KX495695 \\
\hline B. majalis & Spain: Madrid: Valdepiélagos $\star$ & Ber117 & KX495690 \\
\hline B. majalis & Spain: Madrid: Valdepiélagos $\star$ & Ber118 & KX495691 \\
\hline B. majalis & Spain: Madrid: Valdepiélagos $\star$ & Ber127 & KX495692 \\
\hline B. majalis & Spain: Segovia: Navafría & MAB143 & KX495722 \\
\hline B. majalis & Spain: Segovia: Prádena & MAB129 & KX495715 \\
\hline B. majalis & Spain: Toledo: 2 km NE El Emperador & MAB120 & KX495711 \\
\hline B. majalis & Spain: Toledo: 2 km NE El Emperador & MAB122 & KC853102 \\
\hline B. majalis & Spain: Toledo: 2 km NE El Emperador & MAB173 & KC853103 \\
\hline B. majalis & Spain: Toledo: 2 km O Urda & MAB170 & KX495736 \\
\hline B. majalis & Spain: Toledo: 2 km O Urda & MAB171 & KX495737 \\
\hline B. majalis & Spain: Toledo: 6 km N El Emperador & MAB148 & KX495725 \\
\hline B. majalis & Spain: Toledo: Zarza de Tajo $\star$ & Ber101 & KX495686 \\
\hline B. majalis & Spain: Toledo: Zarza de Tajo $\star$ & Ber103 & KX495687 \\
\hline B. majalis & Spain: Toledo: Zarza de Tajo $\star$ & Ber104 & KX495688 \\
\hline B. majalis & Spain: Valencia: Camporrobles & MAB112 & KX495707 \\
\hline B. majalis & Spain: Valladolid: San Miguel del Arroyo & MAB106 & KX495704 \\
\hline B. majalis & Spain: Valladolid: San Miguel del Arroyo & MAB128 & KX495714 \\
\hline B. majalis & Spain: Valladolid: San Miguel del Arroyo & MAB144 & KX495723 \\
\hline B. majalis & Spain: Valladolid: San Miguel del Arroyo & MAB154 & KX495728 \\
\hline
\end{tabular}

Note: All specimens were collected by the authors from 2001 to 2012. Stars indicate populations and specimens selected for cantharidin content analyses.

nitrile gloves. Haemolymph extraction was performed twice. The first extraction was after $2-4$ days in captivity $(n=72)$ and the second extraction $(n=24)$ was after 8-10 days (Table S1). A haemolymph sample (0.4-10.2 g) was diluted with hexane $(0.5 \mathrm{~mL})$ and homogenized with dichloromethane $(0.5 \mathrm{~mL})$ in glass tubes with Teflon caps. Then, the samples were sonicated (Elma Transonic 700) for $3 \mathrm{~min}$.

To analyse the relationships between cantharidin content and phylogeny, 58 specimens were used to estimate cantharidin content per gram of dry weight. The sample consisted of individuals subjected to nonhaemolymph extraction $(n=14)$, one haemolymph extraction ( $n=28)$, and two haemolymph extractions ( $n=16$, Table S1). Individuals were frozen and then lyophilized. Body dry weight was determined after 48 $\mathrm{h}$ of freeze drying in a VIRTIS 25 LE-53 GENESIS SQ. Lyophilized individuals (0.057-0.725 g) were transferred to a Teflon digestion reactor with hydrochloric acid ( $3 \mathrm{~mL}$ ) and were heated to $120{ }^{\circ} \mathrm{C}$ for $3 \mathrm{~h}$. Once the reactor was cooled its content was added to chloroform $(5 \mathrm{~mL})$, followed by vortex mixing for $15 \mathrm{~s}$. Once phases were separated, the lower layer of chloroform was collected with a Pasteur pipette. The procedure was repeated twice for each individual to ensure complete extraction.

Samples of haemolymph and lyophilized individuals were placed in $2 \mathrm{~mL}$ vials for analysis by gas chromatography coupled to mass spectrometry (GC-MS). The GC-MS system consisted of a Thermo Finnigan Trace GC 2000 coupled with a Trace MS mass selective detector. The chromatographic conditions were controlled using the Xcalibur software v. 1.2 (Thermo Finnigan, San Jose, CA). The GC column was a SLB-5 ms (30 m × $0.32 \mathrm{~mm}, 0.25 \mu \mathrm{m}$, Supelco Analytical, Bellefonte, PA). The flow rate of helium was $0.8 \mathrm{~mL} /$ 


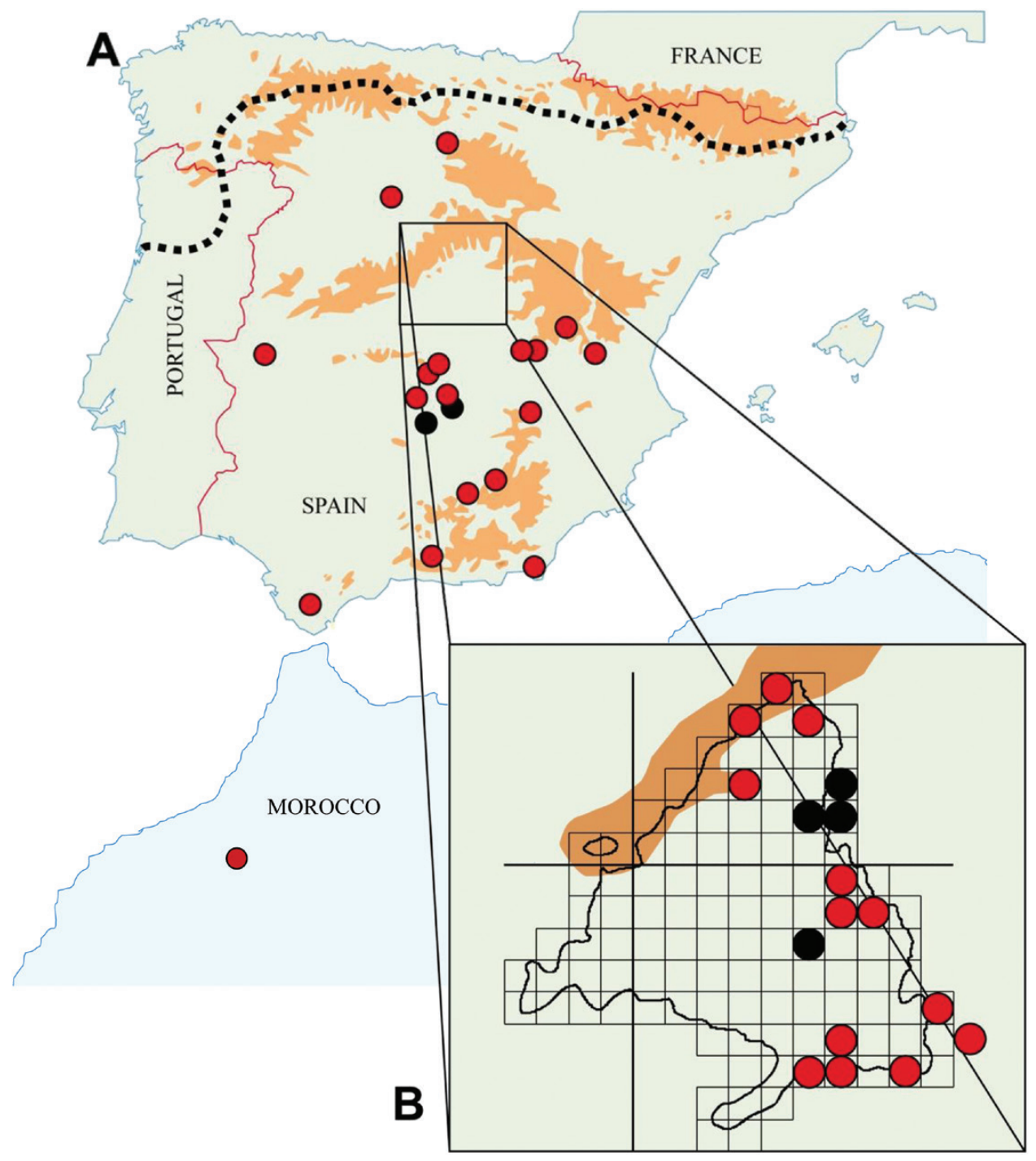

Figure 2. Study area showing the sampling localities of red-striped (red dots) and entirely black populations (black dots) of Berberomeloe majalis. (A) Specimens for phylogeographic and phylogenetic analyses. (B) Specimens for cantharidin content analyses. Dotted line represents the northern limit of the species distribution.

min. The injection volume was $1 \mu \mathrm{L}$ in splitless mode for $2 \mathrm{~min}$. Injector conditions were $250^{\circ} \mathrm{C}$ in constant flow mode. The column oven had an initial temperature of $50^{\circ} \mathrm{C}$ for $2 \mathrm{~min}$. The subsequent temperature was programmed at a heating rate of $10^{\circ} \mathrm{C} / \mathrm{min}$ to $310^{\circ} \mathrm{C}$. The final temperature was held isothermally for $5 \mathrm{~min}$. Total run time was $30 \mathrm{~min}$. Cantharidin detection was performed by selected ion monitoring, registering $\mathrm{m} / \mathrm{e} 128$ which is the majority ion of cantharidin's mass spectra. Cantharidin identification was performed by comparison with mass spectra available in NIST MS search 2.0 library. Confirmation and quantification was achieved with the retention time and calibration curves (range: $0.015-48 \mu \mathrm{g} / \mathrm{mL}$, slope: $476.401, r^{2}=0.999$ ) obtained from the injection of cantharidin standard purchased from Sigma-Aldrich (St. Louis, MO).

\section{STATISTICAL ANALYSES}

Phylogenetic analyses were carried out under Maximum Likelihood (ML) and Bayesian Inference (BI) frameworks. ML analyses were estimated with RAxML (Stamatakis, Hoover \& Rougemont, 2008) using 1000 bootstrap replicates to assess node support. BI analyses were performed using MrBayes 3.2.2 (Ronquist et al., 2012). We ran different analyses with the partition scheme suggested in PartitionFinder (Lanfear et al., 2012, 2014) with partitions cox1_PoS1 1-655/3, cox1_PoS2 12-656/3, and cox1_PoS3 3-657/3). 
We explored the substitution model space with the option lset $\mathrm{nst}=$ mixed rates=invgamma. To estimate the posterior probabilities of all the parameters, we ran four Markov Chains Monte Carlo (MCMC) for $100 \times 10^{6}$ generations sampling every 10000 generations, in two independent runs (for further details see Percino-Daniel et al., 2013). To generate the final phylogenetic hypothesis, we discarded $25 \%$ of the obtained trees as burn-in, and generated an annotated 50\% Majority Rule consensus tree in MrBayes.

By using a Bayesian-coalescence approach implemented in BEAST 1.8.2 (Drummond et al., 2012), we estimated divergence times between lineages within $B$. majalis. Given the absence of fossil records for the species, we calibrated the molecular clock using the substitution rates for cox1 estimated in Papadopoulou, Anastasiou \& Vogler (2010). We ran the analyses for 100 $\times 10^{6}$ sampling every 10000 generations, under a lognormal relaxed molecular clock, a HKY + I + G substitution model calculated in JModelTest v.2 (Darriba et al., 2012) and under a Birth-Death Incomplete Sampling speciation tree prior (Stadler, 2009). To encompass the pairwise differentiation range of 2.3-3.54\% (Papadopoulou et al., 2010), we specified as a prior the substitution rates for cox1: lognormal distribution in real space with initial value $=0.015 \log ($ Mean $)=0.015 \log (S D)=0.2$. We examined the trace plots and Effective Sample Size values in Tracer v.1.5. to evaluate the convergence of the MCMC. The results were summarized and annotated in a maximum clade credibility tree generated in TreeAnnotator (Drummond et al., 2012), previously removing the first 25\% as burn-in. Haplotype networks for cox1 marker to Iberian Peninsula populations were constructed with HaploViewer, which converts a BI tree into a haplotype genealogy (available at http://www. cibiv.at/ \%20greg/haploviewer).

Ancestral character states were reconstructed in RASP (Yu et al., 2015), with the aim of analyzing the ancestral state of red-striped coloration within B. majalis. We performed BBM (Bayesian Binary MCMC) analyses implemented in RASP v.3.2 (Ali et al., 2012; Yu et al., 2015). As an input we introduced the consensus tree from BEAST with branch lengths in units of time and we assigned A for red-striped specimens and B for entirely black specimens. We ran ten MCMC chains simultaneously for $5 \times 10^{4}$ generations, sampling every 100 steps and discarding the first 100 samples as burn-in.

We identified variables that significantly affected the cantharidin content in haemolymph using general linear mixed-effects models (LMM, McCullagh \& Nelder, 1989). In the model we included cantharidin content in haemolymph $(\mu \mathrm{g} / \mathrm{g})$ as a dependent variable, and sex (male, female), morphotype (red-striped and entirely black) locality, and extraction (a single extraction, two sequential extractions) as independent variables. The individual was fitted as a random factor in the models.
Following Zuur, Ieno \& Smith (2007), we compared beyond optimal models (the most complex models, with all factors and their plausible interactions) with different random error structure using the restricted ML estimation procedure. Once the random structure was defined, we determined the fixed effects structure using ML. Model averaging was performed because more than one model had $\triangle \mathrm{AICc}<2$ (Table S2). The variance explained was estimated by calculating the marginal $R^{2}$ $\left(R_{m}^{2}\right.$ : variance explained by the fixed factors) and conditional $R^{2}\left(R_{c}^{2}\right.$ : variance explained by both the fixed and random factors, Nakagawa \& Schielzeth, 2013).

Differences in cantharidin content of body dry weight (mg/g d. w.) was analyzed with a general linear model (GLM); the variables sex (male, female), morphotype (with red stripes, entirely black), and number of extractions ( 0,1 or 2 extractions) were defined as independent variables. The dependent variable was log-transformed to better conform to assumptions of normality and homogeneity of variance. Effect of locality on cantharidin content of dry weight body was analyzed with a non-parametric Kruskal-Wallis test. The sample was split by sex and morphotype, so differences in cantharidin content in body dry weight between localities were analyzed within same sex and same morphotype.

We also performed Generalized Estimating Equations (GEE) to analyse the statistical relationship between cantharidin content and morphotype (red-striped and entirely black) taking into account their phylogenetic relationship (Paradis \& Claude, 2002). We performed these analyses using the function 'compar.gee' in $R$ package 'ape' (Paradis, Claude \& Strimmer, 2004). GEE models are suitable for data with discrete response variables through the specification of binomial error structure. The response variable was morphotype (entirely black, red-striped) and the mean cantharidin content in haemolymph per population $(n=6)$ was defined as independent variable. A simplified distance-based phylogenetic analysis was calculated using Neighbor Joining algorithms with PAUP v 4.0a146 (Swofford, 2002). The resulting topology was edited and exported to Newick format in FigTree v.1.4.0.

We verified the normal distribution of LMM and GLM model residuals visually by checking normal probability plots and with Shapiro-Wilk test. We verified the homogeneity of variances and goodness of fit by plotting residuals vs. fitted values. These analyses were carried out in $R$ version 2.15.0. Simple statistics are reported in the main text as mean \pm SD.

\section{RESULTS}

\section{CANTHARIDIN CONTENT RESULTS}

Model-averaging of cantharidin content in haemolymph included sex and number of extractions as significant 
factors (Table 2). Cantharidin content in haemolymph did not depend on morphotype and locality $(P>0.05$; Table 2). Cantharidin content in haemolymph was significantly higher in males $(80.9 \pm 106.5 \mu \mathrm{g} / \mathrm{g})$ than in females $(20.0 \pm 41.5 \mu \mathrm{g} / \mathrm{g}$; Table 2 and Fig. 3$)$. Cantharidin content in haemolymph was also significantly higher in the second than in the first extraction in both sexes (first extraction: $33.76 \pm 53.11 \mu \mathrm{g} / \mathrm{g}$; second extraction: $135.36+143.49 \mu \mathrm{g} / \mathrm{g}$; Fig. 3 ). Finally, the content of cantharidin in dried bodies was also significantly higher in males (males: $64.22 \pm 51.28 \mathrm{mg} / \mathrm{g} \mathrm{d}$. w; females: $9.10 \pm 12.64 \mathrm{mg} / \mathrm{g} \mathrm{d}$. w; $\left.F_{1,48}=49.9, P<0.001\right)$, with no significant effects on morphotype $\left(F_{1,48}=0.681\right.$, $P=0.413)$ and number of extractions $\left(F_{2,48}=0.863, P=\right.$ 0.428 ). Locality had no significant effect on cantharidin content in dry weight body either in entirely black populations (females: $\chi^{2}=0.10, P=0.752$, males: $\chi^{2}=0.61, P$ $=0.736)$ or in red-striped populations (females: $\chi^{2}=0.72$, $P=0.157$, males: $\chi^{2}=0.41, P=0.522$ ). The GEE model showed that cantharidin content in dry weight body did not depend on morphotype $(t=-0.24, P=0.848)$.

\section{PHYLOGENETIC RESULTS}

Sequences of $657 \mathrm{bp}$ of the Cytochrome Oxidase I mitochondrial gene (cox1) were obtained for 63 specimens of Iberian $B$. majalis. The phylogenetic analysis set under ML (bootstrap support, BS) and BI (posterior probabilities, PP) methods yielded a topology that reflects three major clades (Fig. 4). A poorly supported Clade A included samples from the red-striped populations of various localities in central Spain, together with entirely black specimens from Ciudad Real. Clade $B$ included only red-striped specimens and showed two subclades, the first from western and southern Spain ( $\mathrm{PP}=1 ; \mathrm{BS}=86)$, and the second from Almería in southern Spain and Oumallal in the Middle Atlas. Clade $\mathrm{C}$ was the only strongly supported monophyletic clade $(\mathrm{PP}=1 ; \mathrm{BS}=99)$, split into two subclades. The first subclade $(\mathrm{PP}=1 ; \mathrm{BS}=91)$ grouped entirely black specimens from Guadalajara (Uceda, Valdepiélagos) and Madrid (Talamanca), together with red-striped individuals from Madrid (Meco, Daganzo de Arriba), all of them in central Spain (Fig. 2, inset). The second subclade grouped mainly red-striped specimens from northern Spain $(\mathrm{PP}=0.89 ; \mathrm{BS}=95)$, together with a black specimen from Madrid (Rivas de Jarama). Redstriped and entirely black morphotypes were mixed across the phylogeny within clades A and C. Groupings reflect geographic structure rather than coloration patterns (see the following text on network analyses).

The haplotype network, which includes the 49 cox 1 haplotypes obtained, shows that the mtDNA variability in $B$. majalis is well structured geographically (Fig. 5A). No clear pattern of segregation was observed among entirely black and red-striped specimens (Fig. 5B). In fact, entirely black specimens from Guadalajara (Uceda) and one red-striped specimen from Madrid (Daganzo de Arriba) shared the same haplotype (Fig. 5B). Time to the most recent common ancestors (TMRCA) for the known Berberomeloe species was placed about the end of the Miocene (Fig. 6).

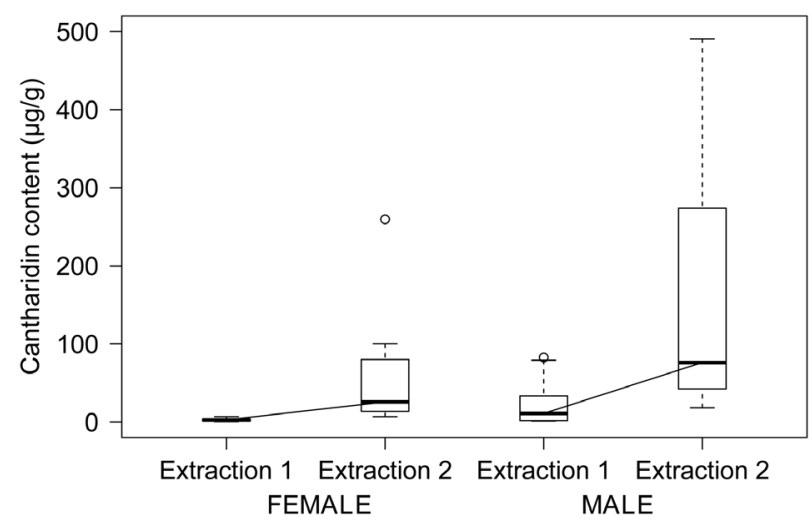

Figure 3. Sexual differences in cantharidin content in haemolymph $(\mu \mathrm{g} / \mathrm{g})$ of $B$. majalis individuals subjected to two haemolymph extractions.

Table 2. Model-averaging for cantharidin content in haemolymph of Berberomeloe majalis as a function of sex, morphotypes, locality, and number of cantharidin extraction.

\begin{tabular}{lcrr}
\hline Fixed effects & Estimate \pm SE & $z$-value & $P$-value \\
\hline Intercept & $-0.03 \pm 0.40$ & 0.07 & 0.947 \\
$N$ extractions & $0.99 \pm 0.15$ & 6.39 & $<0.001$ \\
Sex (male) & $0.71 \pm 0.22$ & 3.28 & 0.001 \\
Morphotype & $-0.07 \pm 0.61$ & 0.11 & 0.912 \\
Locality (Colmenar de Oreja) & $-0.70 \pm 0.38$ & 1.84 & 0.066 \\
Locality (Talamanca de Jarama) & $-0.31 \pm 0.17$ & 1.73 & 0.083 \\
Locality (Valdehornos) & $-0.35 \pm 0.39$ & 0.88 & 0.379 \\
Locality (Zarza de Tajo) & $0.11 \pm 0.38$ & 0.29 & 0.773 \\
Sex $\times N$ extractions & $-0.29 \pm 0.23$ & 1.16 & 0.246 \\
\hline
\end{tabular}




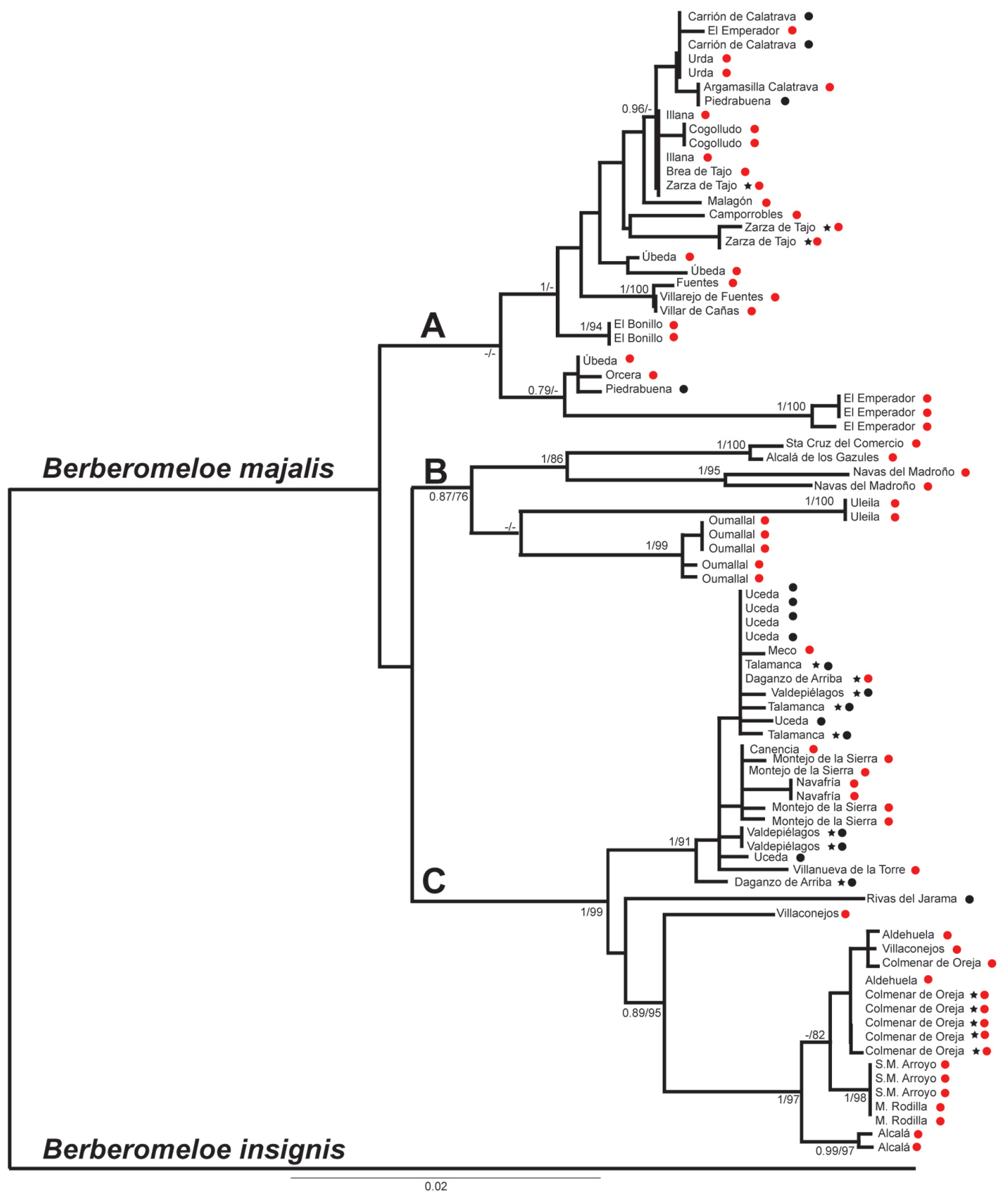

Figure 4. Phylogenetic relationships among Iberian populations of Berberomeloe majalis. Bayesian phylogenetic tree based on $657 \mathrm{bp}$ of cox $1 \mathrm{mtDNA}$ sequences. Support for each node is represented by the posterior probabilities (PP) resulting from the Bayesian Inference analysis and the bootstrap support values (BS) obtained for the Maximum Likelihood tree (PP/ $\mathrm{BS})$. The dots on the right side correspond to the two colour morphs: black dots represent entirely black specimens and red dots represent red-striped specimens. Stars indicate populations and specimens selected for cantharidin content analyses.

Differentiation of the main clades within B. majalis occurred during the Pliocene-Pleistocene transition 2.94 Mya (95\% HPD: 1.31-5.15). TMRCA for entirely black specimens occurred about 1.13 Mya (95\% HPD: 0.46-2.1) and the rate of diversification increased at the Upper Pleistocene about 0.8-0.5 Mya. 


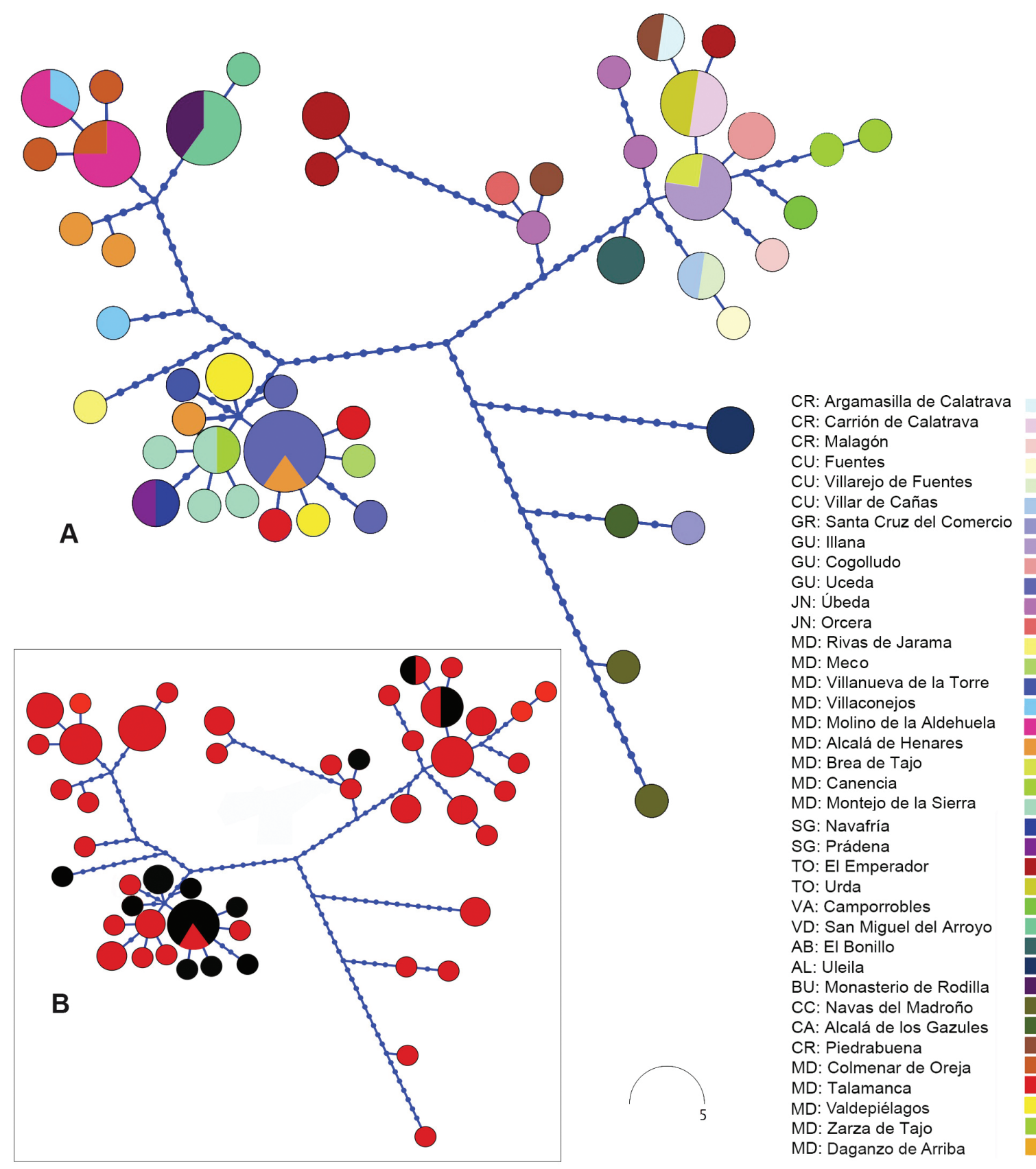

Figure 5. Mitochondrial cox1 haplotype network of Berberomeloe majalis lineages within the Iberian Peninsula (49 haplotypes). The size of the circles (haplotypes) is proportional to the number of individuals presenting each haplotype. (A) The different colors assign haplotypes to the geographical location reported in Table 1. (B) Black and red lineages from the haplotype network correspond to the two colour morphs (red-striped vs. entirely black specimens).

The ancestral character reconstruction showed that red-striped coloration is ancestral for B. majalis. The oldest node representing the most recent common ancestor of black specimens is more recent than that representing red-striped coloration, which appears as an ancestral character in all clades (Fig. S1).

\section{DISCUSSION}

Our results revealed that the cantharidin content in $B$. majalis is influenced by sex and haemolymph extraction, but does not differ between morphotypes, nor across phylogeographic lineages. Cantharidin content was always higher in males than in females, 


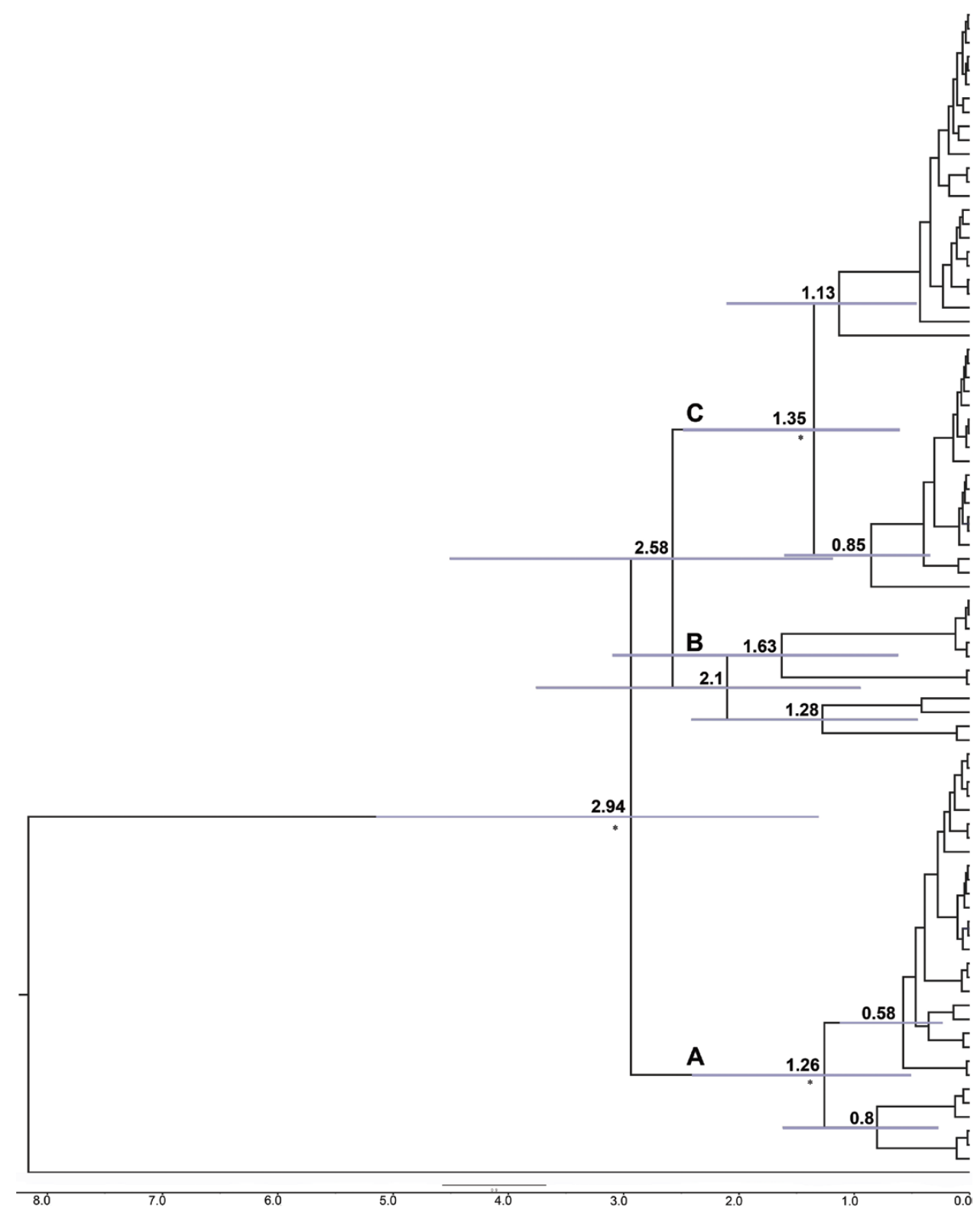

Figure 6. Temporal estimates (95\% high probability intervals - HPD) depicted in the phylogenetic tree generated in a Bayesian-coalescence framework for Berberomeloe majalis. Blue bars at nodes indicate the $95 \%$ highest posterior density (HPD) intervals and units of $X$-axis reflect Mya. Asterisks correspond to posterior probabilities values over 0.95.

suggesting that the amount of this toxic compound could be under sexual selection rather than under predator deterrence pressures. On the other hand, the cantharidin content in haemolymph increased significantly in the second extraction in both sexes. Previous studies suggest that cantharidin biosynthesis occurs during early stages of ontogenetic development, and that females are unable to synthesize this toxin, obtaining it from males during copulation (Sierra et al., 1976; Holz et al., 1994). However, our results showed an increase in cantharidin content in haemolymph in females, which could only be explained by their ability to either concentrate cantharidin in haemolymph or synthesize cantharidin themselves. Our results support this latter possibility, that is that females are also able to synthesize cantharidin. First, the cantharidin content measured as dry weight per beetle was higher than in haemolymph, which suggests that beetles may accumulate cantharidin somewhere in their bodies, and that they are able to mobilize this toxin towards haemolymph. Second, if females received a finite amount 
of cantharidin from males during copulation, the cantharidin content of females would show a clear decrease between successive haemolymph extractions. However, extraction factor did not significantly influence the cantharidin content in dry weight of beetle. Our data support the suggestions from previous authors, that is females may be able to synthesize this toxin independently of the males' nuptial transfer (Nikbakhtzadeh et al., 2012), as well as the earlier proposed mechanisms of cantharidin synthesis in blister beetles (Yin \& Jin, 2010).

The occurrence of red over black patterns has appeared multiple times along the phylogeny of meloid beetles (Pinto \& Bologna, 1999; Bologna \& Pinto, 2002), but striped patterns over exposed heavy abdominal segments are less common. Species of the genus Megetra in North American deserts and B. majalis in the western Palearctic share both heavy exposed abdomens and conspicuous red stripes over them (Fig. 1). Phylogenetic analyses of Meloidae did not show a close relationship between Megetra and Berberomeloe. In fact, the two clades in which these genera are included are not sister groups and belong to different tribes (Bologna et al., 2008). Evolution of the striped pattern is thus homoplastic, probably as a consequence of convergence in a system subjected to strong selective pressures (Wu et al., 2010).

Phylogenetic analyses reveal that changes in coloration are recent, and indicate that that red-striped coloration is ancestral for B. majalis. TMRCA for clades including black specimens dated back to the Pleistocene. Red-striped and entirely black populations of B. majalis occur together in three main clades, two of them separated for at least 2.6 My (over the Pliocene-Pleistocene limit). Most populations within these lineages showed the typical red-striped conspicuous coloration pattern, while populations composed of entirely black specimens are scattered all over the geographic range of the species. Red-striped patterns occur through all lineages, including those relating directly to the basal split within the species (Fig. 4). This shows that red-striped coloration is ancestral for B. majalis, that is it evolved in the ancestor of all current lineages within the species (Fig. S1). The lack of monophyly of entirely black populations indicates a multiple homoplastic origin for the entirely black coloration, which emerged independently on multiple occasions. Percentage of cox 1 sequence divergence across entirely black and red-striped neighbouring populations is similar to the divergence found within red-striped populations, suggesting that a possible genetic isolation among them is the result of recent demographic or isolating events. Lack of monophyly and absence of genetic isolation support the hypothesis of a recent loss of the striped pattern across the entire geographic range of the species.
Cantharidin content does not differ significantly between red-striped and entirely black populations, or across phylogeographic lineages in $B$. majalis. These results point to a decoupling of coloration and toxicity, consistent with the widespread presence of cantharidin in Meloidae, independent of the conspicuousness of their coloration. However, predators avoid unprofitable preys if they are markedly visible (Roper \& Redston, 1987; Prudic, Skemp \& Papaj, 2007). Entirely black coloration is frequent among large non-poisonous Mediterranean beetles that share habitat and activity with Berberomeloe, that is tenebrionoid beetles of the genera Pimelia and Akis, which are frequent prey of diurnal and nocturnal predators, respectively (Hódar, Campos \& Rosales, 1996; Tigar \& Osborne, 2000; Del Bove \& Isotti, 2001; SánchezPiñero, 2007; Bravo et al., 2016), suggesting that black coloration and large size do not deter predators. The existence of toxic populations composed of entirely black specimens within the red-striped lineages suggests that the selective pressures that maintained the red-striped coloration were either not related to visual predation, or alternatively, selective pressures became relaxed in recent times, when entirely black populations appeared. Although a few predators tolerate cantharidin toxicity (Eisner et al., 1990; Bartram \& Boland, 2001; Bravo et al., 2014, 2016), reports on blister beetle predation are very scarce (see Bologna, 1991).

In sum, the phylogenetic analyses show that changes in coloration of $B$. majalis are recent, and therefore that the ancient pressures that fixed and maintained red-striped colorations in this species are no longer acting today. However, these changes in coloration are not correlated with changes in cantharidin content (i.e. entirely black specimens and red-striped are equally poisonous), suggesting that the evolution of colour polymorphisms in B. majalis is decoupled from toxicity.

\section{ACKNOWLEDGEMENTS}

We are grateful to the late Marina Alcobendas for her invaluable assistance in the laboratory. L. Cuadra and E. Fernández for carrying out chromatography analysis (Laboratorio de cromatografía MNCN-CSIC). We thank three anonymous reviewers for their comments. Research for this study was funded by grant CGL2010-15786, CGL2008-02567, CGL2012-36345, and CGL2015-66571-P (MINECO/FEDER). The regional environmental agencies of Castilla-La Mancha, CastillaLeón, Extremadura, Andalucía, Valencia, and Madrid (Spain) provided the permits to collect blister beetles.

\section{References}

Alcobendas M, Ruíz JL, Settanni C, García-París M. 2008. Taxonomic status of Euzonitis haroldi (Heyden, 
1870) (Coleoptera: Meloidae) inferred from morphological and molecular data. Zootaxa 1741: 59-67.

Ali SS, Yu Y, Pfosser M, Wetschnig W. 2012. Inferences of biogeographical histories within subfamily Hyacinthoideae using S-DIVA and Bayesian binary MCMC analysis implemented in RASP (Reconstruct Ancestral State in Phylogenies). Annals of Botany 109: 95-107.

Aronsson M, Gamberale-Stille G. 2008. Domestic chicks primarily attend to colour, not pattern, when learning an aposematic coloration. Animal Behaviour 75: 417-423.

Ayasse M, Paxton RJ, Tengö J. 2001. Mating behavior and chemical communication in the order Hymenoptera. Annual Review of Entomology 46: 31-78.

Bahme A. 1968. Cantharides toxicosis in the equine. Southwestern Veterinarian 21: 147-149.

Barr AC, Wigle WL, Flory W, Alldredge BE, Reagor JC. 1998. Cantharidin poisoning of emu chicks by ingestion of Pyrota insulata. Journal of Veterinary Diagnostic Investigation 10: 77-79.

Bartram S, Boland W. 2001. Chemistry and ecology of toxic birds. ChemBioChem 2: 809-811.

Beasley VR, Wolf GA, Fischer DC, Ray AC, Edwards WC. 1983. Cantharidin toxicosis in horses. Journal of the American Veterinary Medical Association 182: 283-284.

Beltrán M, Jiggins CD, Bull V, Linares M, Mallet J, McMillan WO, Bermingham E. 2002. Phylogenetic discordance at the species boundary: comparative gene genealogies among rapidly radiating Heliconius butterflies. Molecular Biology and Evolution 19: 2176-2190.

Blanco G, Bertellotti M. 2002. Differential predation by mammals and birds: implications for egg-colour polymorphism in a nomadic breeding seabird. Biological Journal of the Linnean Society 75: 137-146.

Blodgett SL, Carrel JE, Higgins RA. 1991. Cantharidin content of blister beetles (Coleoptera, Meloidae) collected from Kansas alfalfa and implications for inducing cantharidiasis. Environmental Entomology 20: 776-780.

Blomberg SP, Garland T. 2002. Tempo and mode in evolution: phylogenetic inertia, adaptation and comparative methods. Journal of Evolutionary Biology 15: 899-910.

Bologna MA. 1989. Berberomeloe, a new west mediterranean genus of Lyttini for Meloe majalis Linée (Coleoptera, Meloidae) - systematics and bionomics. Bollettino Di Zoologia 55: 359-366.

Bologna MA. 1991. Coleoptera Meloidae. Fauna d'Italia. XXVIII. Bologna: Calderini, XIV+541 pp.

Bologna MA, Oliverio M, Pitzalis M, Mariottini P. 2008. Phylogeny and evolutionary history of the blister beetles (Coleoptera, Meloidae). Molecular Phylogenetics and Evolution 48: 679-693.

Bologna MA, Pinto JD. 2002. The Old World genera of Meloidae (Coleoptera): a key and synopsis. Journal of Natural History 36: 2013-2102.

Bond AB, Kamil AC. 2006. Spatial heterogeneity, predator cognition, and the evolution of color polymorphism in virtual prey. Proceedings of the National Academy of Sciences of the United States of America 103: 3214-3219.

Bravo C, Bautista LM, García-París M, Blanco G, Alonso JC. 2014. Males of a strongly polygynous species consume more poisonous food than females. PLs One 9: e111057.
Bravo C, Ponce C, Bautista LM, Alonso JC. 2016. Dietary divergence in the most sexually size-dimorphic bird. Auk 133: $178-197$.

Brower AVZ. 1996. Parallel race formation and the evolution of mimicry in Heliconius butterflies: a phylogenetic hypothesis from mitochondrial DNA sequences. Evolution 50: 195-221.

Capinera JL, Gardner DR, Stermitz FR. 1985. Cantharidin levels in blister beetles (Coleoptera, Meloidae) associated with alfalfa in Colorado. Journal of Economic Entomology 78: 1052-1055.

Carrel JE. 1999. Contrasting responses of southern house spiders and raccoons to blister beetle prey. Journal of Chemical Ecology 25: 1295-1303.

Carrel JE, Eisner T. 1974. Cantharidin: potent feeding deterrent to insects. Science 183: 755-757.

Carrel JE, McCairel MH, Slagle AJ, Doom JP, Brill J, McCormick JP. 1993. Cantharidin production in a blister beetle. Experientia 49: 171-174.

Cooper WE Jr. 2008. Tandem evolution of diet and chemosensory responses in snakes. Amphibia-Reptilia 29: 393-398.

Darriba D, Taboada GL, Doallo R, Posada D. 2012. jModelTest 2: more models, new heuristics and parallel computing. Nature Methods 9: 772.

Darst CR, Cummings ME, Cannatella DC. 2006. A mechanism for diversity in warning signals: conspicuousness versus toxicity in poison frogs. Proceedings of the National Academy of Sciences of the United States of America 103: $5852-5857$.

Del Bove E, Isotti R. 2001. The European badger (Meles meles) diet in a Mediterranean area. Hystrix 12: 19-25.

Dettner K. 1997. Inter- and intraspecific transfer of toxic insect compound cantharidin. In: Dettner K, Bauer G, Völkl W, eds. Vertical food web interactions. Heidelberg, Berlin: Springer, 115-145.

Drummond AJ, Suchard MA, Xie D, Rambaut A. 2012. Bayesian phylogenetics with BEAUti and the BEAST 1.7. Molecular Biology and Evolution 29: 1969-1973.

Eisner T, Conner J, Carrel JE, McCormick JP, Slagle AJ, Gans C, O'Reilly JC. 1990. Systemic retention of ingested cantharidin by frogs. Chemoecology 1: 57-62.

Eisner T, Meinwald J. 1995. The chemistry of sexual selection. Proceedings of the National Academy of Sciences of the United States of America 92: 50-55.

Endler JA. 1978. A predator's view of animal colour patterns. Evolutionary Biology (New York) 11: 319-364.

Folmer O, Black M, Hoeh W, Lutz R, Vrijenhoek R. 1994. DNA primers for amplification of mitochondrial cytochrome c oxidase subunit I from diverse metazoan invertebrates. Molecular Marine Biology and Biotechnology 3: 294-299.

Gamberale-Stille G, Guilford T. 2004. Automimicry destabilizes aposematism: predator sample-and-reject behaviour may provide a solution. Proceedings of the Royal Society B-Biological Sciences 271: 2621-2625.

Gamberale-Stille G, Tullberg BS. 1999. Experienced chicks show biased avoidance of stronger signals: an experiment with natural colour variation in live aposematic prey. Evolutionary Ecology 13: 579-589. 
García-París M. 1998. Revisión sistemática del género Berberomeloe Bologna, 1988 (Coleoptera, Meloidae) y diagnosis de un endemismo ibérico olvidado. Graellsia 54: 97-109.

Harvey PH, Bull JJ, Pemberton M, Paxton RJ. 1982. The evolution of aposematic coloration in distasteful prey: a family model. American Naturalist 119: 710-719.

Hódar JA, Campos F, Rosales BA. 1996. Trophic ecology of the Ocellated Lizard Lacerta lepida in an arid zone of southern Spain: relationships with availability and daily activity of prey. Journal of Arid Environments 33: 95-107.

Holz C, Streil G, Dettner K, Dutemeyer J, Boland W. 1994. Intersexual transfer of a toxic terpenoid during copulation and its paternal allocation to developmental stages: quantification of cantharidin in cantharidin-producing oedemerids (Coleoptera, Oedemeridae) and canthariphilous pyrochroids (Coleoptera, Pyrochroidae). Zeitschrift Fur Naturforschung C: A Journal of Biosciences 49: 856-864.

Lanfear R, Calcott B, Ho SY, Guindon S. 2012. Partitionfinder: combined selection of partitioning schemes and substitution models for phylogenetic analyses. Molecular Biology and Evolution 29: 1695-1701.

Lanfear R, Calcott B, Kainer D, Mayer C, Stamatakis A. 2014. Selecting optimal partitioning schemes for phylogenomic datasets. BMC Evolutionary Biology 14: 82.

Lindstedt C, Eager H, Ihalainen E, Kahilainen A, Stevens M, Mappes J. 2011. Direction and strength of selection by predators for the color of the aposematic wood tiger moth. Behavioral Ecology 22: 580-587.

Machordom A, Araújo R, Erpenbeck D, Ramos MA. 2003. Phylogeography and conservation genetics of endangered European Margaritiferidae (Bivalvia: Unionoidea). Biological Journal of the Linnean Society 78: 235-252.

Maddison WP, Maddison DR. 2015. Mesquite: a modular system for evolutionary analysis. Version $3.04 \mathrm{ed}$. Available at: http://mesquiteproject.org.

Mappes J, Marples N, Endler JA. 2005. The complex business of survival by aposematism. Trends in Ecology \& Evolution 20: 598-603.

Martínez-Solano I, Teixeira J, Buckley D, García-París M. 2006. Mitochondrial DNA phylogeography of Lissotriton boscai (Caudata, Salamandridae): evidence for old, multiple refugia in an Iberian endemic. Molecular Ecology 15: 3375-3388.

McCullagh P, Nelder JA. 1989. Generalized linear model. London: Chapman \& Hall.

Mebs D, Pogoda W, Schneider M, Kauert G. 2009. Cantharidin and demethylcantharidin (Palasonin) content of blister beetles (Coleoptera: Meloidae) from southern Africa. Toxicon 53: 466-468.

Nakagawa S, Schielzeth H. 2013. A general and simple method for obtaining R2 from generalized linear mixedeffects models. Methods in Ecology and Evolution 4: 133-142.

Nikbakhtzadeh MR, Tirgari S. 2002. Cantharidin component of Iranian blister beetle (Coleoptera: Meloidae) and their differences between Iranian and exotics species. Iranian Journal of Public Health 31: 113-117.

Nikbakhtzadeh MR, Vahedi M, Vatandoost H, Mehdinia A. 2012. Origin, transfer and distribution of cantharidin-related compounds in the blister beetle Hycleus scabiosae. Journal of Venomous Animals and Toxins Including Tropical Diseases 18: 88-96.

Papadopoulou A, Anastasiou I, Vogler AP. 2010. Revisiting the insect mitochondrial molecular clock: the mid-Aegean trench calibration. Molecular Biology and Evolution 27: 1659-1672.

Paradis E, Claude J. 2002. Analysis of comparative data using generalized estimating equations. Journal of Theoretical Biology 218: 175-185.

Paradis E, Claude J, Strimmer K. 2004. APE: analyses of phylogenetics and evolution in $\mathrm{R}$ language. Bioinformatics 20: 289-290.

Percino-Daniel N, Buckley D, García-París M. 2013. Pharmacological properties of blister beetles (Coleoptera: Meloidae) promoted their integration into the cultural heritage of native rural Spain as inferred by vernacular names diversity, traditions, and mitochondrial DNA. Journal of Ethnopharmacology 147: 570-583.

Pinto JD. 1975. A taxonomic study of the genus Tegrodera (Coleoptera: Meloidae). The Canadian Entomologist 107: $45-66$.

Pinto JD. 1984. Cladistic and phenetic estimates of relationship among genera of Eupomphine blister beetles (Coleoptera, Meloidae). Systematic Entomology 9: 165-182.

Pinto JD, Bologna MA. 1999. The New World genera of Meloidae (Coleoptera): a key and synopsis. Journal of Natural History 33: 569-620.

Prudic KL, Skemp AK, Papaj DR. 2007. Aposematic coloration, luminance contrast, and the benefits of conspicuousness. Behavioral Ecology 18: 41-46.

Ray AC, Post LO, Hurst JM, Edwards WC, Reagor JC. 1980. Evaluation of an analytical method for the diagnosis of cantharidin toxicosis due to ingestion of blister beetles (Epicauta lemniscata) by horses and sheep. American Journal of Veterinary Research 41: 932-933.

Ronquist F, Teslenko M, van der Mark P, Ayres DL, Darling A, Höhna S, Larget B, Liu L, Suchard MA, Huelsenbeck JP. 2012. MrBayes 3.2: efficient Bayesian phylogenetic inference and model choice across a large model space. Systematic Biology 61: 539-542.

Roper TJ. 1990. Responses of domestic chicks to artificially colored insect prey: effects of previous experience and background color. Animal Behaviour 39: 466-473.

Roper TJ, Redston S. 1987. Conspicuousness of distasteful prey affects the strength and durability of one-trial avoidance-learning. Animal Behaviour 35: 739-747.

Rowe C, Lindstrom L, Lyytinen A. 2004. The importance of pattern similarity between Mullerian mimics in predator avoidance learning. Proceedings of the Royal Society B-Biological Sciences 271: 407-413.

Sánchez-Piñero F. 2007. Predation of Scarabaeus cristatus F. (Coleoptera, Scarabaeidae) by jerboas (Jaculus sp.: Rodentia, Dipodidae) in a Saharan sand dune ecosystem. Zoologica Baetica 18: 69-72.

Selander RB. 1965. A taxonomic revision of genus Megetra (Coleoptera - Meloidae) with ecological and behavioral notes. Canadian Entomologist 97: 561-580. 
Sierra JR, Woggon WD, Schmid H. 1976. Transfer cantharidin (1) during copulation from the adult male to the female Lytta vesicatoria (Spanish fly). Experientia 32: 142-144.

Skelhorn J, Rowe C. 2010. Birds learn to use distastefulness as a signal of toxicity. Proceedings of the Royal Society B: Biological Sciences 277: 1729-1734.

Stadler T. 2009. On incomplete sampling under birth-death models and connections to the sampling-based coalescent. Journal of Theoretical Biology 261: 58-66.

Stamatakis A, Hoover P, Rougemont J. 2008. A rapid bootstrap algorithm for the RAxML Web servers. Systematic Biology 57: 758-771.

Summers K, Clough ME. 2001. The evolution of coloration and toxicity in the poison frog family (Dendrobatidae). Proceedings of the National Academy of Sciences of the United States of America 98: 6227-6232.

Swofford DL. 2002. PAUP*. Phylogenetic Analysis Using Parsimony (*and Other Methods). Sunderland, MA: Sinauer Associates.

Tigar BJ, Osborne PE. 2000. Invertebrate diet of the Houbara Bustard Chlamydotis undulata macqueenii in $\mathrm{Abu}$ Dhabi from calibrated faecal analysis. Ibis 142: 466-475.
Varley GC. 1939. The frightening attitude of two Californian Meloid beetles Phodaga alticeps Lec. and Tegrodera erosa Lec. Proceedings of the Royal Entomological Society of London (A) 14: 101-102.

Weldon PJ. 2013. Chemical aposematism. Chemoecology 23: 201-202.

Weldon PJ, Burghardt GM. 2015. Evolving detente: the origin of warning signals via concurrent reciprocal selection. Biological Journal of the Linnean Society 116: 239-246.

Wu Y, Wang Y, Jiang K, Chen X, Hanken J. 2010. Homoplastic evolution of external colouration in Asian stout newts (Pachytriton) inferred from molecular phylogeny. Zoologica Scripta 39: 9-22.

Yin Y-P, Jin G-X. 2010. Biosynthesis, transfer and biological function of cantharidin in blister beetles (Coleoptera: Meloidae). Acta Entomologica Sinica 53: 1305-1313.

Yu Y, Harris AJ, Blair C, He X. 2015. RASP (Reconstruct Ancestral State in Phylogenies): a tool for historical biogeography. Molecular Phylogenetics and Evolution 87: $46-49$.

Zuur AF, Ieno EN, Smith GM. 2007. Analysing ecological data. New York: Springer.

\section{SUPPORTING INFORMATION}

Additional Supporting Information may be found in the online version of this article at the publisher's website:

Table S1. Sample sizes of haemolymph samples and lyophilized individuals according to sex and morphotypes (entirely black, red-striped) with non-haemolymph extraction (extraction 0 ), in the first extraction (2-4 days after capture) and the second extraction (8-10 days after capture).

Table S2. Candidate linear mixed-models (LMMs) for cantharidin content in haemolymph of B. majalis as a function of sex, morphotypes, and number of cantharidin extraction. Model selection was based on the Akaike's Information Criterion corrected for small sample sizes (AICc). Delta ( $\triangle \mathrm{AICc}$ ) and weight values (wAICc) for each AICc are also shown. Marginal $R^{2}\left(R_{m}^{2}\right.$; proportion of variance explained by the fixed factors alone $)$ and conditional $R^{2}\left(R^{2}\right.$; proportion of variance explained by both the fixed and random factors) were computed for each model using methods described by Nakagawa \& Schielzeth (2013).

Figure S1. Ancestral character reconstruction with temporal estimates on the Bayesian-coalescence tree (BEAST). The red colour corresponds to red-stripped morphotypes, black colour to entirely black morphotypes, and blue for both morphotypes. The ancestral character reconstruction showed the red-striped coloration is ancestral for B. majalis. Clades A, B, and C are enlarged to allow visual inspection. 


\section{SUPPORTING INFORMATION}

Additional Supporting Information may be found in the online version of this article at the publisher's website:

Table S1. Sample sizes of haemolymph samples and lyophilized individuals according to sex and morphotypes (entirely black, redstriped) with non-haemolymph extraction (extraction 0), in the first extraction (2-4 days after capture) and the second extraction (8-10 days after capture).

\begin{tabular}{|c|c|c|c|c|c|c|}
\hline \multirow{2}{*}{ Test } & \multirow{2}{*}{ Extraction } & \multicolumn{2}{|c|}{ Entirely black } & \multicolumn{2}{|c|}{ Red-stripes } & \multirow{2}{*}{ Total } \\
\hline & & Female & Male & Female & Male & \\
\hline \multirow[t]{2}{*}{ Haemolymph } & 1 & 23 & 27 & 11 & 11 & 72 \\
\hline & 2 & 5 & 12 & 4 & 3 & 24 \\
\hline \multirow[t]{3}{*}{ Body } & 0 & 4 & 3 & 4 & 3 & 14 \\
\hline & 1 & 7 & 9 & 5 & 7 & 28 \\
\hline & 2 & 3 & 7 & 4 & 2 & 16 \\
\hline
\end{tabular}

Table S2. Candidate linear mixed-models (LMMs) for cantharidin content in haemolymph of B. majalis as a function of sex, morphotypes, and number of cantharidin extraction. Model selection was based on the Akaike's Information Criterion corrected for small sample sizes (AICc). Delta ( $\mathrm{AICc}$ ) and weight values (wAICc) for each AICc are also shown. Marginal $R^{2}\left(R_{\mathrm{m}}^{2}\right.$; proportion of variance explained by the fixed factors alone) and conditional $R^{2}\left(R_{\mathrm{c}}^{2}\right.$; proportion of variance explained by both the fixed and random factors) were computed for each model using methods described by Nakagawa and Schielzeth (2013).

\begin{tabular}{|c|c|c|c|c|c|c|c|}
\hline \multicolumn{2}{|c|}{ Candidate models } & \multirow{2}{*}{$\frac{\mathrm{df}}{5}$} & \multirow{2}{*}{$\frac{\mathrm{AICc}}{208.3}$} & \multirow{2}{*}{$\frac{\Delta \mathrm{AICc}}{0.0}$} & \multirow{2}{*}{$\frac{\text { wAICc }}{0.42}$} & \multirow{2}{*}{$\frac{\mathrm{R}^{2}{ }_{m}}{0.51}$} & \multirow{2}{*}{$\frac{\mathrm{R}^{2} c}{0.67}$} \\
\hline 1) & $\mathrm{N}$ extractions + Sex $+\mathrm{N}$ extractions $*$ Sex & & & & & & \\
\hline 2) & $\begin{array}{l}\mathrm{N} \text { extractions }+\mathrm{Sex}+\text { Morphotype }+\mathrm{N} \text { extractions } * \mathrm{Sex}+\mathrm{Sex} \text { * } \\
\text { Morphotype }+\mathrm{N} \text { extractions * Morphotype }\end{array}$ & 14 & 208.7 & 0.4 & 0.34 & 0.46 & 0.69 \\
\hline 3) & $\mathrm{N}$ extractions & 6 & 209.4 & 1.2 & 0.23 & 0.45 & 0.68 \\
\hline 4) & Sex & 10 & 217.4 & 9.1 & 0.00 & 0.49 & 0.69 \\
\hline 5) & $\mathrm{N}$ extractions + Morphotype $+\mathrm{N}$ extractions ${ }^{*}$ Morphotype & 4 & 238.8 & 30.5 & 0.00 & 0.25 & 0.25 \\
\hline
\end{tabular}


Figure S1. Ancestral character reconstruction with temporal estimates on the Bayesian-coalescence tree (BEAST). Red colour corresponds to red-stripped morphotypes, black to entirely black morphotypes and blue for both morphotypes. The ancestral character reconstruction showed that red-striped coloration is ancestral for B.majalis. Clades A, B and C are enlarge to allow visual inspection.
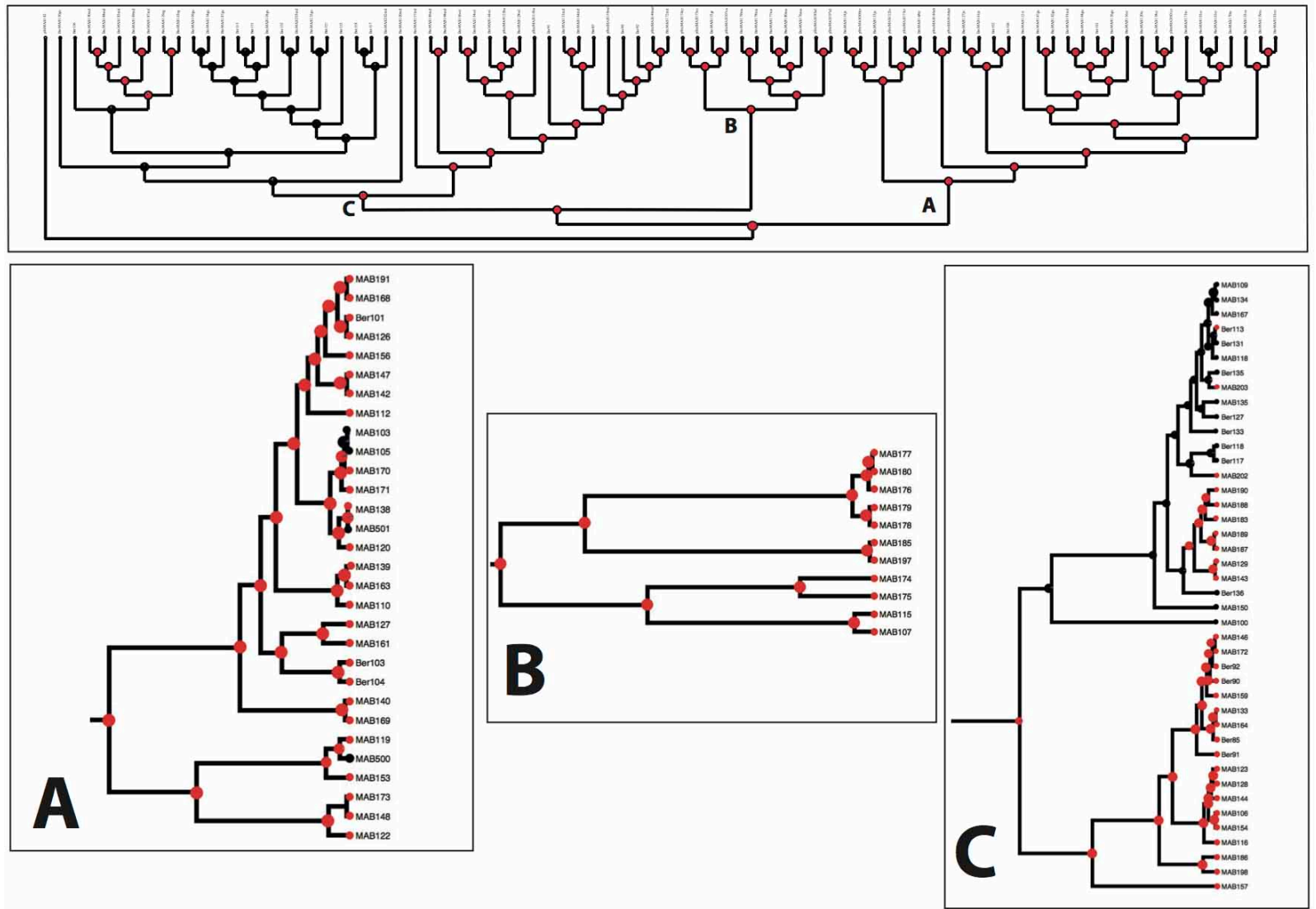